OPEN ACCESS

Edited and reviewed by: Berent Prakken,

Utrecht University, Netherlands

*Correspondence:

Meta Roestenberg

m.roestenberg@/umc.nl

Specialty section

This article was submitted to

Translational Medicine,

a section of the journa

Frontiers in Medicine

Received: 09 January 2019

Accepted: 25 January 2019

Published: 14 February 2019

Citation:

Roestenberg M, Kamerling IMC and de Visser SJ (2019) Corrigendum:

Controlled Human Infections As a Tool

to Reduce Uncertainty in Clinical

Vaccine Development

Front. Med. 6:23

doi: $10.3389 /$ fmed.2019.00023

\section{Corrigendum: Controlled Human Infections As a Tool to Reduce Uncertainty in Clinical Vaccine Development}

\author{
Meta Roestenberg ${ }^{1 *}$, Ingrid M. C. Kamerling ${ }^{2}$ and Saco J. de Visser ${ }^{3}$ \\ ${ }^{1}$ Department of Parasitology and Infectious Diseases, Leiden University Medical Center, Leiden, Netherlands, ${ }^{2}$ Centre for \\ Human Drug Research, Leiden, Netherlands, ${ }^{3}$ Paul Janssen Futurelab, Leiden, Netherlands
}

Keywords: vaccine, malaria, product development (PD) process, clinical development, low-income access

\section{A Corrigendum on}

Controlled Human Infections As a Tool to Reduce Uncertainty in Clinical Vaccine Development

Roestenberg, M., Kamerling, I. M. C., and de Visser, S. J. (2018). Front. Med. 5:297. doi: 10.3389/fmed.2018.00297

In the original article, there was a mistake in "Figure $2 \mathrm{C}$ " as published. In the figure legend, the incorrect number was used to indicate the second-best route and should have been " $5.22 € \mathrm{M}$ " instead of " $5.97 € \mathrm{M}$ ". The corrected Figure $2 \mathrm{C}$ appears below.

The authors apologize for this error and state that this does not change the scientific conclusions of the article in any way. The original article has been updated.

Copyright () 2019 Roestenberg, Kamerling and de Visser. This is an open-access article distributed under the terms of the Creative Commons Attribution License (CC BY). The use, distribution or reproduction in other forums is permitted, provided the original author(s) and the copyright owner(s) are credited and that the original publication in this journal is cited, in accordance with accepted academic practice. No use, distribution or reproduction is permitted which does not comply with these terms. 


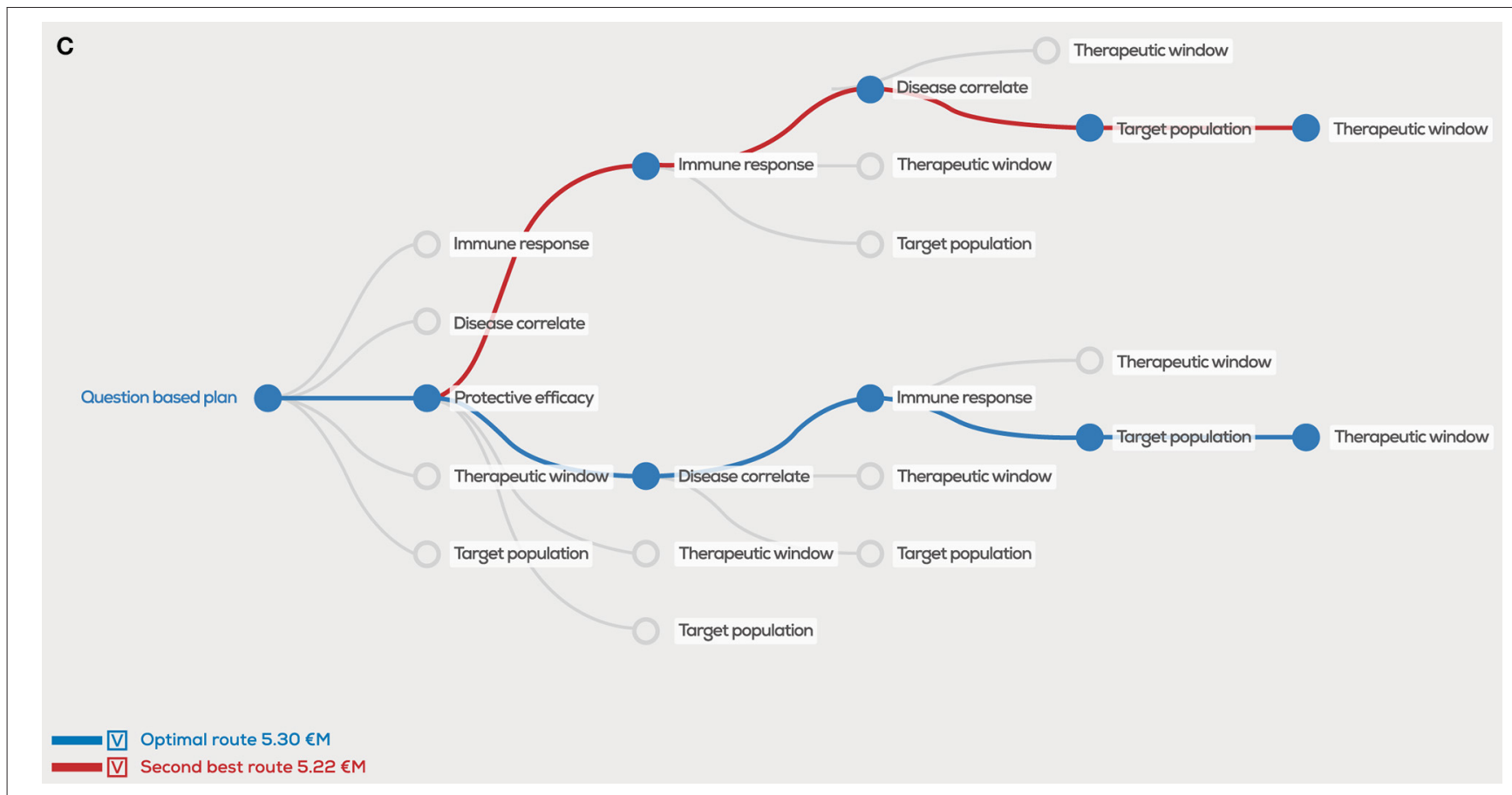

FIGURE 2 | Decision tree showing the optimal order of questions to generate the highest project value, given estimated probability of success (PoS) and costs (million euro, $€ \mathrm{M})$ per scientific question. In the case PoS and costs for every question are equal, the order does not matter for the project value (A), however unequal distributions will clearly show different project values for the optimal order in blue, second best order in red and user defined order in green (B). A $1 € M$ additional investment in "correlates" has a major effect on the optimal order and project value (C). 